\title{
EL USO DEL LENGUAJE, MÁS ALLÁ DE LAS NORMAS
}

The use of language, beyond the rules

\author{
ELIZABETH MonTENEGRo GUEVARA* \\ Universidad Politécnica Salesiana/Ecuador \\ Imontenegro@ups.edu.ec
}

\begin{abstract}
Resumen
Este trabajo pretende establecer un paralelo entre la Psicología Social y la Psicología del Lenguaje, entendiendo que ambas están reguladas por normas y pautas sociales más allá de lo prescriptivo y normativo, implícitas en las normas institucionales sobre el uso del lenguaje y la semántica del discurso utilizada en la actualidad.

El presente trabajo pretende comprender a través de una revisión bibliográfica la norma descriptiva del lenguaje en contraste con la norma institucional o prescriptiva, con el fin de realizar un análisis sobre la comunicación actual, los usos del lenguaje y las formas de expresión, en relación con las normas impuestas institucionalmente, pasando por una revisión de las diferentes propuestas en torno a las normas y el desarrollo de las mismas, desde las normas sociales hasta la norma perversa, sin dejar de lado la explicación del lenguaje, usos y funciones.

En la primera parte se presenta una descripción de las teorías en torno a las normas, concretamente se realizará un recorrido desde las normas sociales a la norma perversa, y se vinculará esta propuesta de la Psicología Social a la Psicología del Lenguaje, revisando las normas descriptivas y prescriptivas en torno al uso del lenguaje propuestas por la Real Academia de la Lengua.

La segunda parte presenta un análisis sobre el lenguaje, sus funciones como requisitos indispensables en el proceso comunicativo, enfatizando sobre todo los niveles sintáctico y pragmático que permitirán la posterior expresión del lenguaje.
\end{abstract}

Finalmente se plantea y se discute la relación entre ambas, para entender al lenguaje como un proceso y producto de la persona.

Palabras claves

Psicología Social, Psicología del Lenguaje, normas, norma perversa, semántica, discurso.

Forma sugerida de citar: Montenegro Guevara, Elizabeth (2016). El uso del lenguaje, más allá de las normas. Sophia, colección de la Filosofía de la Educación, 20(1), pp. 245-264.

* Psicóloga Educativa. Magíster en Educación Especial. Docente en las carreras de Pedagogía y de Filosofía y Pedagogía en la Universidad Politécnica Salesiana. PhD (c) en Psicología. 


\section{Abstract}

This paper aims to establishing a parallel between Social Psychology and Psychology of Language, understanding that both are regulated by social norms and beyond prescriptive and regulatory guidelines, implicit in the institutional rules on the use of language and discourse semantics used today.

This paper aims to understand through a literature review descriptive standard language as opposed to institutional or prescriptive standard, in order to perform an analysis of the current communication, the uses of language and forms of expression, in relation to the standards imposed institutionally, through a review of the different proposals on standards and their development, from social norms to the perverse rule, in addition with the explanation of language, uses and functions.

In the first part of the paper, its presented a description of the theories about standards from social norms to the perverse rule, and this proposal from the Social Psychology of the Psychology of Language will be linked by reviewing the descriptive rules and prescriptive about the use of the proposals by the Royal Academy of Language.

The second part of the paper presents a language analysis, functions as a prerequisite in the communication process, emphasizing especially syntactic and pragmatic levels that allow subsequent expression of language.

Finally the relationship between them is discussed, to understand the language as a process and product of the person.

Keywords

Social Psychology, Psychology of Language, standards, perverse rule, semantics, discourse.

\section{Introducción}

El diccionario de la Real Academia de la Lengua Española (2010), define a la norma como la regla que se debe seguir o a que se deben ajustar las conductas, tareas, actividades, etc.; por lo tanto, estas señalan el modo de obrar de una persona. Existen normas que son autoimpuestas por los propios individuos, este tipo de normas están basadas en las escalas de valores de los sujetos, existen además, otro tipo de normas que son establecidas por la sociedad y tienen como propósito principal alcanzar el bien común.

Desde el punto de vista de la Psicología Social las normas sociales constituyen un proceso interactivo que originan patrones de conducta compartidos. Fernandez Dols (1993), realiza un interesante recorrido histórico en torno a la definición y delimitación de las "normas sociales"; menciona a Sumner (1906), como uno de los autores anglosajones precursores de la diferenciación terminológica de la norma. En 1936, Sheriff define a la norma como un marco de referencia que se origina de una manera espontánea cuando los individuos deben enfrentarse a situaciones ambiguas. En 1963 Homans habla de las normas como un juicio compartido entre los miembros de un grupo en relación a lo que se debe hacer, así como las sanciones que su incumplimiento originarán. En Europa, por otra parte, en 1989, Apfelbaum, plantea que las normas 
son impuestas por los grupos de poder para discriminar y sojuzgar a los miembros de otros grupos dominados.

En años más recientes, Cialdini \& Kallgren (1990), señalan que son los grupos quienes producen sus propias normas, y que serán estas las que permitan a los individuos adaptarse adecuadamente al medio, los autores identifican en los sujetos dos puntos de referencia normativos: la percepción sobre la conducta que los miembros de la sociedad o del grupo esperan de él y la percepción acerca de la conducta que se puede observar en esos grupos.

Finalmente, Fernández Dols, plantea que las normas sociales, formales e informales no siempre son generadas por el propio grupo y, aún en el caso de que lo sean, no siempre poseen una clara funcionalidad. Con frecuencia pueden ser disfuncionales y acarrear graves problemas para la supervivencia del propio grupo (Fernández Dols, 1993, p. 92).

En este sentido, el autor, propone el concepto de "norma perversa", no como un tipo especial de norma, la perversidad no tiene que ver con la prohibición o el fomento de ciertos comportamientos, tampoco se refiere a normas intrínsecamente malas; más bien el concepto de norma perversa hace referencia a un grupo de normas que pueden estar presenten en todo tipo de sociedades y que buscan regular diversos comportamientos. En tanto que la perversidad se centra en los efectos que la norma puede provocar bajo determinadas circunstancias.

El lenguaje es una construcción social, en tanto en cuanto permite la interacción con los demás, en ese sentido, también está sujeto a este proceso normativo descrito en los párrafos precedentes. Así como las normas fueron en un principio prescripciones orales hasta convertirse en normas institucionalizadas y organizadas en códigos o reglas de conducta, las lenguas también fueron en un inicio habladas, así la transmisión oral era la única vía de compartir el conocimiento (Elkartea, 2010); pero, en algún momento, al ser humano le pareció insuficiente.

Con el surgimiento de las civilizaciones, las organizaciones sociales se fueron haciendo cada vez más compleja, y se hizo patente la necesidad de establecer normas y de hacer que estas fueran accesibles para quienes las necesitaban (Elkartea, 2010, p. 11), de esta manera surge la escritura, sin embargo, al existir un sinnúmero de lenguas, los alfabetos escritos también debieron ser varios, al centrar la atención en el idioma español, es la Real Academia de la Lengua, la que ha procurado normalizar el uso de esta lengua, en sus diferentes acepciones.

Las normas propuestas por esta institución pueden identificarse dentro de las normas institucionales para regular el uso correcto de la lengua; pero en términos generales las normativas para el uso del lenguaje no siempre son utilizadas y mucho menos respetadas por la comuni- 
dad hablante, quién ha originado una suerte de su propia gramática, la misma que va mucho más allá de la región donde ésta se desarrolle, en este sentido, la comunidad busca nuevas formas de expresión propias del momento histórico en el cual se encuentra, de la edad, de los intereses, de la educación y en la actualidad las nuevas formas de comunicación propias de las herramientas tecnológicas utilizadas, como las redes sociales por ejemplo; al respecto, basta observar éstas últimas llenas de faltas ortográficas, de sustituciones de palabras, de cambios en las estructuras sintácticas que a pesar de transgredir las normas gramaticales, son muy aceptadas y difundidas como formas comunicativas.

Así, siguiendo esta línea de pensamiento y si bien es cierto, el término de "norma perversa" es utilizado para hacer referencia a las diversas normativas impuestas en la sociedad, cabría preguntarse si esté término no se encuentra también vigente en el contexto del uso del lenguaje, en tanto en cuanto como se ha expuesto en líneas anteriores, parecería que en la actualidad el uso correcto del lenguaje ha perdido su vigencia y se prioriza ahora el manejo de formas lingüísticas meramente utilitarias, arbitrarias que desdibujan la riqueza del idioma español y transgreden de alguna manera todas las reglas ortográficas vigentes. ¿Será entonces que existe también en la comunicación una suerte de normas perversas, que son necesarias identificar y manejarlas dentro del contexto de la producción escrita como vía de comunicación?

Por tanto, el objetivo de este trabajo es realizar una reflexión, estableciendo un paralelo entre la Psicología Social y la Psicología del Lenguaje, entendiendo que ambas están reguladas por normas y pautas sociales más allá de lo prescriptivo y normativo, implícitas en las normas institucionales sobre el uso del lenguaje y la semántica del discurso utilizada en la actualidad.

El presente trabajo pretende comprender a través de una revisión bibliográfica la norma descriptiva del lenguaje en contraste con la norma institucional o prescriptiva, con el fin de realizar un análisis sobre la comunicación actual, los usos del lenguaje y las formas de expresión, en relación con las normas impuestas institucionalmente, pasando por una revisión de las diferentes propuestas en torno a las normas y el desarrollo de las mismas, desde las normas sociales hasta la norma perversa, sin dejar de lado la explicación del lenguaje, usos y funciones.

En la primera parte se presenta una descripción de las teorías en torno a las normas, concretamente se realizará un recorrido desde las normas sociales a la norma perversa, y se vinculará esta propuesta de la Psicología Social a la Psicología del Lenguaje, revisando las normas descriptivas y prescriptivas en torno al uso del lenguaje propuestas por la Real Academia de la Lengua. 
La segunda parte presenta un análisis sobre el lenguaje, sus funciones como requisitos indispensables en el proceso comunicativo, enfatizando sobre todo los niveles sintáctico y pragmático que permitirán la posterior expresión del lenguaje.

Finalmente se plantea y se discute la relación entre ambas, para entender al lenguaje como un proceso y producto de la persona.

\section{De las normas sociales a la norma perversa}

Beramendi (2013), señala que las normas sociales constituyen representaciones cognitivas de aquellas conductas que se consideran apropiadas o valoradas por las personas (Hogg y Reid, 2006) sirven como marco de referencia para interactuar dentro de una comunidad y realizar juicios de valor (Sherif, 1936/1973), dependen del contexto y del lugar al cual se aplican (Rakoczy \&Schmidt, 2013) y por su incumplimiento se recibe una sanción (Cialdini, 2007). Es posible, entonces, enfatizar la importancia de las normas sociales, dentro de la comunidad en la cual el sujeto se encuentra inmerso, puesto que será esta misma comunidad, la que sancione si el individuo no se ciñe a la normativa impuesta, la sanción mencionada involucra además el juicio y valor moral que puede tener un mayor impacto y connotación para el sujeto en cuestión.

Desde el punto de vista de la Psicología no se estudian las normas en sí mismas, sino las creencias normativas de las personas y cómo ello repercute en la dinámica social.

Así, Cialdini (2007), afirma que las normas sociales se estudian desde tres perspectivas:

a. Los marcos de referencia compartidos a través de los cuáles los actores interactúan socialmente.

b. La uniformidad de conducta sobre los estándares de comportamiento e implican la necesidad de uniformidad social; $y$,

c. La presión social por cumplir que supone expectativas de comportamiento.

Bicchieri (2006) menciona que existen cuatro condiciones para que una norma social pueda existir, estas son: contingencia, expectativas empíricas, expectativas normativas y preferencias condicionales. Cada una de estas condiciones guarda estrecha relación e interacción y determinarán el comportamiento del sujeto, así como también la aceptación, aprobación o rechazo de la sociedad si estas no se cumplen tal como han sido establecidas.

Las condiciones para que la norma social exista son: Tomar R como una norma comportamental para situaciones del tipo $\mathrm{S}$, donde $\mathrm{S}$ puede ser 
representado como un juego de mezcla motivacional. Podemos decir que $\mathrm{R}$ es una norma social en la población $\mathrm{P}$, si existe un conjunto suficientemente largo de población individual:

Contingencia: yo conozco que la regla existe y se aplica para situaciones de tipo $S$.

Preferencia condicional: prefiero estar de acuerdo con $\mathrm{R}$ en situaciones de tipo $\mathrm{S}$ en las siguientes condiciones: a) Expectativas empíricas (...) b) Expectativas normativas (...) (Bicchieri, 2006, p. 11).

Elster (1997), por su parte supone dos condiciones para que una norma sea considerada social: (a) compartida por otras personas y (b) parcialmente sostenidas por la aprobación y la desaprobación de ellas (p. 121). Al respecto, el contexto de desaprobación se esperaría que tenga para el individuo una gran repercusión en su conducta y en la forma de interactuar con el medio, dado que todo sujeto al pertenecer a una comunidad, busca la aprobación y la afirmación de sus acciones y conductas en función de la calificación que su contexto inmediato le proporcione.

En tal sentido, la norma entendida como un conjunto de reglas, no se puede establecer por imposición, sino que ha de ajustarse a "los principios de generalización y aceptación social” (Hernández, 2006, p. 36).

En las sociedades, los sujetos evalúan permanentemente si las normas establecidas son justas, es decir si existe una relación legítima entre las autoridades y las instituciones; cuando esta evaluación no es congruente, entonces las personas pierden la confianza en el sistema y dejan de cumplir con las normas; aunque este principio se aplica principalmente al ámbito legal, Beramendi y Zubieta (2014) afirman que puede homologarse con cualquier imagen de autoridad, esta constante evaluación es fundamental en la manera en que los individuos desarrollarán conductas posteriores, pues las mismas se verán o no reforzadas, estimuladas y hasta mantenidas en función de la retroalimentación que reciban, especialmente de las imágenes de autoridad.

Las autoras citan a Fehr y Fischbacher para explicar este fenómeno a partir de comprender que las normas legales o formales están subsumidas por normas sociales que regulan y estipulan un funcionamiento social más profundo sobre el cumplimiento normativo. Por lo cual, más allá de la formalidad de las normas si no hay regulación social que las resguarde, no van a funcionar, hasta convivirán y generarán contradicciones en el sistema mismo (p. 125).

Ahora bien, es posible encontrar un conjunto de normas que a pesar de ser planteadas, sistemáticamente empiezan a ser incumplidas por los sujetos de una comunidad. La norma es considerada, entonces, como un criterio relativamente arbitrario cuya aplicación en contextos complejos -como la sociedad urbana-es la resultante de una constante negociación. 
En este caso, sin embargo, la arbitrariedad llega a cosas tan alta que la norma no se cumple, sin que por ello desaparezca (Fernández Dols, 1992, p. 254); este tipo de norma ha sido denominada por Fernández Dols como "norma perversa"; la norma perversa desmoraliza por igual al grupo con autoridad y al grupo subordinado, disminuye los mecanismos de control social con respecto a otras normas cumplibles y promueve la aparición de una crítica más intensa hacia el que trata de imponer la norma genéricamente que al que se desvía con respecto a esta u otras normas (Fernández Dols, 1992, p. 253).

El término de "norma perversa" se refiere, por tanto, a normas sociales, explícitas, reconocibles y que implican sanciones positivas o negativas. Sin embargo, estas normas poseen la característica peculiar de ser incumplidas sistemáticamente por la mayoría de las personas. Y su perversidad reside en que, a pesar de ser transgredidas de forma general y permanente, se mantienen vigentes y pueden dar lugar a una serie de efectos muy negativos que se resumen en dos conceptos: "desmoralización" y desarrollo de "estructuras sociales alternativas" (Oceja, L., Adarves, I. \& Fernández Dols, J., 2001, p. 27).

$\mathrm{Al}$ respecto, Fernández Dols, enfatiza la presencia de algunas fuentes que originan en los sujetos ciertas conductas y que transgreden las normas establecidas.

- Incompetencia de la autoridad, por falta de eficiencia debido a diversas causas, lo que los hace incapaces de cumplir sus metas y ponen en peligro a la organización.

- Organizaciones sociales complejas que se enfrentan a entornos que cambian rápidamente, las normas se respetaron en un momento y luego son desobedecidas sistemáticamente.Autoridad preocupada por la legitimidad que por la validez de las normas (Fernández Dols, 1992, p. 254).

De lo anteriormente expuesto, se desprenden algunos postulados teóricos que dan cuenta de la presencia o ausencia de ciertas conductas en función de las normas propuestas por la comunidad:

1.1 Teorías sobre el cumplimiento normativo: Beramendi (2013) afirma que en el ámbito de la psicología, el interés por el estudio de las normas se centra no en la estructura de éstas, sino más bien en el análisis sobre le cumplimiento o incumplimiento normativo y a partir de estos criterios, se plantenan las teorías que se describen a continuación: (Beramendi, 2013, p. 8).

1.1.1 Teoría de la conducta planeada: propuesta por Ajzen (1985), propone que la intención de realizar la conduc- 
ta estará mediada por normas subjetivas, donde entrará en juego el análisis de costo-beneficio que realizará el sujeto para recibir la aprobación o no del medio.

1.1.2 Teoría focal de la conducta normativa: propuesta por Cialdini (1990), pone su énfasis en la infuencia social, por lo que plantea dos tipos de normas: la prescriptiva (hace referencia a lo que la persona cree que es lo que se debe hacer) y la descriptiva (que es lo que realmete se hace). Entre ambas se realiza un análisis sobre el control y a sanción social.

1.1.3 Teoría de las normas personales prescriptivas o morales: constituyen normas internalizadas que sirven como parámetros para aprobar la realización de la propia conducta, estas normas van más allá de las repercusiones personales o sociales.

1.1.4 Teoría evaluativa de la conducta normativa (TECNO): propuesta por Oceja, Villegas y Beramendi (2013), plantea que el cumplimiento-incumplimiento de la norma se basa en procesos individuales, en los cuáles el sujeto evalúa su comportamiento sobre las propuestas de acción a partir de dos dimensiones: protección y formalidad, y tienen que ver en cómo la autoridad ha presentado la norma y a la vez esta da al sujeto protección y seguridad.

1.1.5 Teoría de la percepción sobre la legitimidad de la norma: propuesta por Tyler $(2001,2006)$, afirma que la legitimidad es una creencia que supone que una autoridad, institución o norma es apropiada y justa, y esta creencia determina la conducta del sujeto.

1.1.6 Teoría de la cultura de las normas restricitivas-laxas: propuesta por Gelfand y Raver (2006), los autores plantean la idea en que la norma es vista desde una perspectiva cultural, en la cual los estilos culturales normativos son los que condicionan los procesos psicológicos, institucionales y sociales. Esta teoría propone dos componentes de análisis: a) la intensidad de la normas sociales y; b) la fuerza de la sanción.

En los últimos años ha cobrado gran importancia el estudio en torno a la norma perversa, en vista de que son las transgresiones referidas a estas normas las que de alguna manera marcan el comportamiento de los sujetos y su adecuada inclusión y adaptación a la sociedad. Asimismo, el uso del lenguaje podría verse alterado por esta visión, se había men- 
cionado ya, que en la actualidad nos enfrentamos a una comunicación globalizada y a una generación que usa un modo de comunicación que transgrede sistemáticamente las normas impuestas por la Real Academia de la Lengua y que son aceptadas por las comunidades en las cuales se manifiestan. Sería pertinente entonces, analizar algunos aspectos específicos en torno al lenguaje con el fin de procurar dilucidar esta cuestión.

\section{La norma en el uso de la lengua y el lenguaje}

Definir el lenguaje no es tarea sencilla, en la medida es que es una herramienta que posibilita la comunicación, Eysenck (2010), en su libro Psicología Cognitiva, presenta una definición de lenguaje según Harley (2008) y la complementa con lo propuesto por Crystal (1997); el primero señala que el lenguaje es un sistema de símbolos y reglas que hacen posible la comunicación; estas reglas especifican cómo las palabras son ordenadas para formar oraciones (Eysenck, 2010, p. 400); el segundo autor identifica por su parte, ocho funciones del lenguaje y señala que la comunicación es una de ellas.

En efecto, el lenguaje constituye la forma de representar la realidad y de comunicarse, esta manera de concebir al lenguaje, ha permitido pensarlo desde diversos enfoques, como un sistema que ha posibilitado entender la estructura comunicativa y es justamente en este plano donde se centra la reflexión del presente trabajo, puesto que se insertan todos los contenidos normativos de su desarrollo.

Adicionalmente el lenguaje puede ser entendido también como un código en el cual cada uno de los elementos de la comunicación interaccionan e interactúan entre sí para generar la información que se espera trasmitir. Concibiendo por tanto, al lenguaje como una conducta con carácter personal e interpersonal.

Así, es factible utilizar el lenguaje como una manera de expresar el pensamiento, recuperar la información, describir información, realizar onomatopeyas, o expresar la identidad de grupo (Eysenck, 2010, p. 400).

Finalmente, es posible definir al lenguaje:

Como un sistema de símbolos y reglas que nos permite la comunicación, en el que es necesario considerar tres dimensiones importantes: la dimensión estructural (que describe "cómo es" el sistema de símbolos o signos), la dimensión funcional (que tiene que ver con el "para qué" sirve el lenguaje) y la dimensión comportamental (que implica "cómo" se utiliza el lenguaje cuando se comprenden y producen mensajes (Elosúa, 2006, p. 229).

Ferdinand de Saussure en su libro Lingüística General (1916), señalaba que el lenguaje es un fenómeno complejo pues tiene caracterís- 
ticas opuestas: es social e individual, abstracto y concreto, homogéneo y heterogéneo, biológico y mental. Según el autor, el lenguaje tiene dos grandes aspectos: lengua y habla, la primera como el sistema de signos convencionales y la segunda como la realización individual del sistema o de la lengua, en este sentido el habla tendría un carácter eminentemente oral y estaría marcada por el uso individual que cada sujeto tiene al respecto. Por lo tanto, proponía que la manera más objetivable era estudiar la lengua a través del habla del individuo.

El habla constituye la expresión propia, individual que cada sujeto hace de la lengua, es posible encontrar diferentes realizaciones individuales de esta expresión o manifestación, así Montes (1983), habla de argot, que constituye el lenguaje formal usado por los profesionales en sus diferentes campos de aplicación; la jerga que es un lenguaje informal de las personas que se desenvuelven en determinados oficios o actividades. Al lenguaje popular se lo denomina callejero y utiliza modismos para su realización, esta modalidad de habla la encontramos sobre todo en los estratos sociales más bajos. Los dialectos por su parte hacen referencia a la variedad regional de la lengua. Y la norma, finalmente son las reglas que los grupos sociales han establecido y que se las considera dentro de la expresiones lingüísticas más adecuadas.

Tal como lo expresa Montes (1983):

De manera que en el "habla" cabría en principio toda la realización normal o sistemática del código lingüístico, pero también las realizaciones anormales, no convencionales, los errores mismos y la multitud de hechos que sin pertenecer a la convención lingüística se dan en el habla diaria por las circunstancias de la comunicación y que últimamente son objeto de la pragmática (p.326).

Montes hacía referencia al lenguaje oral, sin embargo, como ya se ha manifestado, nos encontraríamos actualmente frente a esta tipología de uso de lenguaje en la expresión escrita, donde aceptando la terminología propuesta, se hablaría de una expresión escrita "callejera" donde se cuentan no solo los modismos propios del lenguaje, sino que además es posible observar nuevas expresiones fonológicas, semánticas, ortográficas y sintácticas, que transgreden la estructura formal y normativa del lenguaje escrito y enfrentan al lector a un mundo nuevo de codificación y decodificación de las palabras y por tanto del mensaje que se busca trasmitir.

Así, el estudio del lenguaje ha pasado desde un paradigma que pone a la lengua como un sistema, a concebir el lenguaje desde la perspectiva de la semiótica social, es decir entenderlo desde la competencia social, donde se privilegian las funciones en diferentes contextos (Van Dijk, 1980). En el mismo sentido, en relación a las teorías que explican la 
adquisición del lenguaje, se ha cursado desde un paradigma conductista a uno neurocognitivista o simbólico; esta transición está ligada a la dimensión adquirida del lenguaje, puesto que con ese mecanismo el sujeto, puede ampliar su mundo lingüístico hacia niveles menos referenciales y pragmáticos, por lo tanto a niveles más simbólicos y más semánticos; este paso, entonces, permite entender la comprensión del lenguaje.

La academia, sin embargo, no es la creadora del lenguaje, pues es la que da fe del uso de la lengua (Martínez De Sousa, 2003); es posible, por tanto definir a la lengua como un sistema complejo de signos, los cuáles se combinan siguiendo una normativa. El uso de la lengua, es el resultado de la convención social, determinado por la herencia cultural y como se mencionó ya anteriormente se adquiere de forma natural.

De esta manera, se considera a la norma lingüística (Elkartea, 2010) como los patrones de uso de la lengua que se aceptan como correctos cuando el hablante transmite el mensaje, esta norma tienen un carácter impositivo pues obliga a usar reglas lingüística concretas; adicionalmente, estas normas crean en la comunidad la idea de hablar bien o mal.

Teniendo en cuenta estos aspectos es posible, definir a la norma lingüística como la convención lingüística tradicionalizada e incluida en el sistema de reglas que hacen y mantienen la cohesión del grupo (Elkartea, 2010).

Estas normas se expresan a través de la gramática; según el texto de Gramática Descriptiva de la Lengua, se define a la gramática:

Como la disciplina que estudia sistemáticamente las clases de palabras, las combinaciones posibles entre ellas y las relaciones entre esas expresiones y los significados que puedan atribuírseles. Esas propiedades, combinaciones y relaciones pueden formularse de maneras diversas y puede haber, por lo tanto, muchas gramáticas de la Gramática de una lengua (Bosque, I. \& Demonte, V., 1999, p. i).

Al respecto, Martínez De Sousa, (2003) analiza las diversas tipologías expuestas en relación a las normas lingüísticas y el uso que estas tienen en el contexto comunicativo.

\subsection{Tipos de normas lingüísticas}

1.2.1 Norma descriptiva, conocida también como consuetudinaria o real, y es la que se comprueba en la actividad de los hablantes, por lo que ésta posibilita las diferentes clasificaciones idiomáticas. Este tipo de norma, no se impone en el grupo por influencias externas, sino que se impone por el mismo grupo. Puede dividirse en dos:

a. Formal en la que si varía la norma, esta no afecta a las posibilidades de distinguir el sistema o el contenido. 
b. Funcional, donde la variación implica cambios en el sentido, en el léxico y la función gramatical. Dentro de la gramática, la norma descriptiva presenta las propiedades de las unidades gramaticales en cada uno de los niveles de análisis: fonética, morfología y sintaxis (Española, 2010, p. 5).

1.2.2 Norma prescriptiva es la que establece los usos que se consideran ejemplares en la lengua culta de una comunidad (Española, 2010, p. 5), es la que se ha formulado por las diferentes instituciones de la lengua que buscan mantener la unidad y uniformidad del idioma.

Es importante destacar que a pesar de que este tipo de norma es la que más se transmite y enseña, no necesariamente se muestra en el habla cotidiana, por tanto, estas constituirán las normas descriptivas del dialecto castellano y aunque están vigentes, en ocasiones son anacrónicas. Así, es difícil precisar las fronteras entre ambas normativas, pues deberán relacionarse con las leyes mínimas del lenguaje.

Al respecto, Demonte (2003), señala que Emilio Alarcos, en el Prólogo de su Gramática de la lengua española (1994) indica también que la gramática normativa es parte de la gramática descriptiva; se incluye en esta, más estrictamente, ya que no puede ya escribirse alejada de ella, pero no se desprende de ella, como quería FR. Por otra parte, su condición es distinta: mientras que la gramática normativa es "provisional y a merced del uso" (.....) la gramática descriptiva "establece ordenadamente ciertos hechos” ( Gramática de la Lengua Española, 1994, p. 20).

En párrafos precedentes, se ha realizado una exposición y análisis en torno a definiciones del lenguaje, habla y las normas que se conocen en su expresión; se había expresado además que una de las funciones del lenguaje es la comunicación, pero en efecto el lenguaje cumple una serie de funciones que han sido estudiadas por diversos autores, las mismas que se exponen más adelante.

\section{El lenguaje y sus funciones}

Desde el punto de vista externo la función comunicativa sirve para transmitir información; es un soporte del pensamiento, puesto que no es posible explicar el pensamiento sin lenguaje pues es justamente este último el que viabiliza la expresión del pensar, finalmente todas estas funciones permiten la interacción social. 
Bühler (1950) propuso un modelo muy importante de las funciones del lenguaje, que guarda relación directa con los elementos de la comunicación que permitirán la función discursiva del lenguaje; el autor presenta tres actores de este proceso:

\section{Emisor (hablante) $\rightarrow$ Mensaje (Asunto) $\rightarrow$ Receptor (Oyente)}

Enfatiza la importancia del signo en el acto comunicativo del cual se generan tres funciones del lenguaje.

a. Función representativa: se refiere a la representación simbólica que el emisor presenta en el acto comunicativo. Al referirse a la función representativa, se expresarán las significaciones que el emisor transmite al receptor. Ejemplo "mesa".

b. Función expresiva: manifiesta el mundo interior del sujeto a través del lenguaje. Ejemplo ¡Qué emoción!

c. Función apelativa: tiene como objetivo principal influir en el comportamiento del receptor. Ejemplo ¿podrías decirme la hora?

El siguiente diagrama representa las funciones del lenguaje propuestas por el autor y su relación con el signo lingüístico.

Figura 1

El signo y las funciones del lenguaje

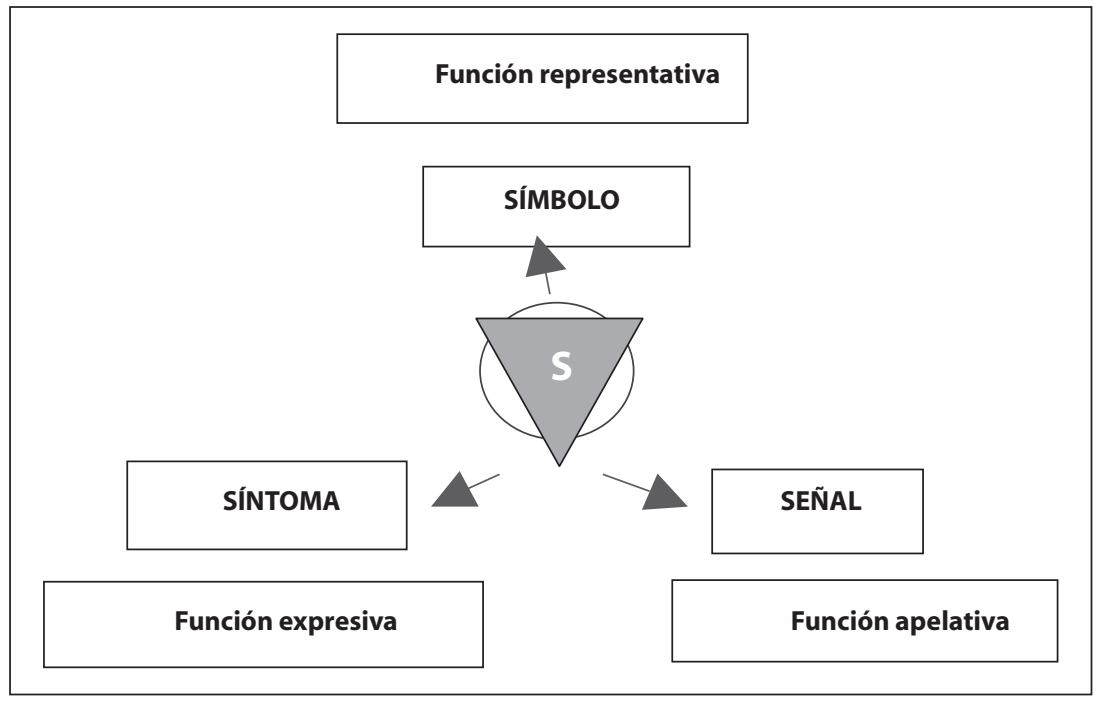

Elaboración: Elizabeth Montenegro G., 2014

Es necesario aclarar, que durante el acto comunicativo, las diferentes funciones presentadas no aparecen interdependientes unas de otras, 
aunque teniendo en cuenta el contexto y el propósito comunicativo, puede primar una sobre las otras.

Posteriormente (Jakobson, 1986), con el desarrollo de la teoría del procesamiento de la información presentada por Shannon y Weaver (1949), Jakobson (1986) describe los componentes del proceso de la comunicación de la siguiente manera:

- Emisor: quién emite el mensaje, es la fuente y transmisor del mensaje.

- Receptor: destinatario del mensaje.

- Mensaje: experiencia que se trasmite.

Sin embargo, para que el mensaje se trasmita eficientemente del emisor al receptor se deberá considerar el contenido que constituye el tema que se desea trasmitir, y el código lingüístico que hace referencia al canal que permite establecer y mantener la comunicación entre el emisor y el receptor.

A partir de este modelo de comunicación, el autor, describe seis funciones, además de las ya propuestas por Bühler (1950).

a. Función emotiva: el emisor manifiesta sentimientos y emociones, usualmente se presenta en primera persona y se utilizan interjecciones, oraciones interrogativas, exclamativas, etc. Ejemplo: ;Qué alegría tengo!

b. Función conativa: tiene como objetivo llamar la atención del receptor, se manifiesta a través de oraciones imperativas o interrogativas. Ejemplo: Esteban, guarda tu ropa.

c. Función referencial: su objetivo es informar sobre algo, comunicar ideas o conceptos, para su realización utiliza oraciones enunciativas, afirmativas o negativas las que suelen presentarse en tercera persona. Ejemplo: Los movimientos de la Tierra son rotación y traslación.

d. Función poética: el objetivo de esta función es producir un impacto en el receptor, pues la manera en la que se trasmite el mensaje. Ejemplo: Un poema de Pablo Neruda.

e. Función metalingüística: tiene como objetivo analizar el lenguaje utilizando el lenguaje. Ejemplo: definir un término.

f. Función fática: hace referencia a la competencia mencionada por Chomsky, es la función que se utiliza constantemente en toda interacción humana, y el propósito de la misma es establecer el canal de comunicación, para iniciarla, mantenerla o suspenderla.

M. Halliday (1979), en su libro El Lenguaje como semiótica social, destaca la importancia de la cultura y la influencia social en el desarrollo 
evolutivo del lenguaje, para lo cual presenta tres fases a las que las denomina según el énfasis en el nivel de lenguaje que se desarrolla: lingüísticoauditivo: fonológico, léxico- gramatical y semántico.

- Fase 1: Lingüística-Auditiva: está caracterizado por el nivel fonológico, en el que aún no se presenta las palabras, sin embargo el niño manifiesta ya un propósito comunicativo, por lo que estarían presentes las siguientes funciones: a. Función instrumental: utiliza la comunicación como un medio de satisfacción de necesidades y deseos. b. Función reguladora: la comunicación se utiliza como una manera de manejar la conducta del otro. c. Función interactiva: permite la interacción comunicativa. d. Función personal: permite la expresión de su propia personalidad. e. Función imaginativa: tiene como propósito crear su propio entorno. f. Función heurística: permite entender a la comunicación como la vía para adquirir conocimientos.

- Fase 2: Léxico-Gramatical: se caracteriza por la transición del nivel léxico-gramatical entre sonido y significado hacia el dominio del principio del diálogo. Las funciones que se presentan en esta etapa son: a. Función matética: constituida por las funciones personal y heurística. El lenguaje es utilizado como una forma de aprendizaje. b. Función pragmática: constituida por las funciones instrumental y reguladora. El lenguaje es utilizado como acción. c. Función Informativa: esta función es la más tardía en aparecer dentro de las microfunciones, y su propósito es transmitir nueva información. Ejemplo: tengo algo que decirte.

- Fase 3: Semántica. Se manifiesta una forma de comunicación similar al lenguaje adulto la misma que se irá complejizándose y desarrollándose a lo largo de la vida. Las funciones que se presentan en esta fase son: a. Función ideacional: representa una macrofunción del lenguaje la que posibilita la manifestación de la experiencia y las relaciones lógicas. b. Función interpersonal: ubica el rol del emisor en el acto comunicativo del discurso y posibilita la interacción con los demás. c. Función textual: presenta la relación del lenguaje consigo mismo y la situación discursiva. d. Función Comunicativa: permite la ampliación del conocimiento y del aprendizaje más allá de la experiencia directa, constituye por tanto una transducción de representaciones mentales con un código serial y la decodificación serial de las proposiciones del lenguaje de la mente.

Como se ha podido evidenciar, el lenguaje cumple diversas funciones las mismas que entrarán en juego en el proceso comunicativo en función de los roles y las necesidades que cada uno de los elementos de la comunicación cumplan en el momento del acto de comunicación. Es justamente en estas necesidades en las que innegablemente entran en juego por una parte las normas que rigen el uso del lenguaje y por otra la intención comunicativa del emisor. 


\section{El uso del lenguaje, más allá de la norma}

En términos generales, se puede entender las diversas realizaciones del habla en diferentes grupos de comunidades, la norma por su parte proporciona un modelo o patrón de ejecución del sistema de convenciones. La lengua como una mera convención, entra así, mediante la norma, en el proceso histórico y en el sistema de normas sociales que conforman y mantienen la cohesión de los grupos sociales en el espacio y en el tiempo (Montes, 1983, p. 329).

Varios autores lingüísticas, psicolingüísticas y sociolingüísticas han reflexionado sobre el uso del lenguaje en la práctica comunicativa; uno de ellos es Martínez De Sousa, quién se refiere a la norma lingüística como el conjunto de reglas restrictivas que definen lo que se debe elegir entre los usos de la lengua si se han de ser fiel a cierto ideal estético o sociocultural (Martínez De Sousa, 2003, p. 1).

El autor señala dentro de esta definición algunos conceptos que avalan la idea de la contravención de la norma en el uso del lenguaje, uno de ellos es el término restrictivo; al respecto Martínez De Sousa (2003) señala la limitación a la cual se encuentran enfrentadas los hablantes en el proceso comunicativo, puesto que ya sea el acto discursivo oral $\mathrm{u}$ escrito, el emisor se verá enfrentado a la limitación expresiva, deberá por tanto seleccionar adecuadamente las palabras que utilizará, para acomodarse apropiadamente a la necesidad comunicativa, adicionalmente, deberá considerar la función comunicativa que le permitirá expresar adecuadamente lo que desea comunicar.

Finalmente, señala que esta comunicación debe ser fiel al ideal estético o sociocultural; es decir, que necesariamente el emisor procurará adecuar su lenguaje a las normas lingüísticas socialmente establecidas con el fin de que lo que ha procurado comunicar sea aceptado.

Ahora bien, el hablante no emite la norma, su función es acatarla, pero en ocasiones parecería que también la ignora; esta norma académica, sin embargo, marca una manera establecida de comunicación y es el hablante quién va a elegir cumplirla o no. En este sentido, el uso del lenguaje se refiere a las realidades lingüísticas descriptivas pero no siguen la norma, lo descriptivo, como ya se ha mencionado en párrafos precedentes, se refiere a la realidad social del lenguaje y da cuenta del aval que recibe esa norma por correcta o incorrecta.

En este sentido, se podría afirmar que ambos lenguajes coexisten casi sin interferir uno sobre otro, así como los actos comunicativos en general, parecen compartidos con el lenguaje normativo sin plantear la idea de corrección o incorreción en su uso. 
Con todos estos antecedentes, estaríamos entonces en posición de responder a las preguntas generadas al inicio de este trabajo, los nuevos textos producidos por esta generación, a la que me he permitido llamar "on line", obedecen a nuevas estructuras organizadas o más bien reorganizadas desde los niveles básicos del lenguaje: el nivel fonológico se ve alterado con el uso, desuso y abuso de ciertos fonemas-grafemas; el nivel semántico con la atribución de nuevos significados a las palabras y más aún la creación de nuevas palabras que posiblemente se acomoden más al uso y utilización de una lengua viva como es el idioma castellano.

A nivel sintáctico, presenciamos la organización de oraciones cada vez más simples, básicas, que son fieles a las expresiones comunicativas actuales, un twitt permite la utilización de 140 caracteres, al igual que un mensaje de texto; un mensaje de whatsapp o un estado, en alguna red social, si bien es cierto permite mayor cantidad de caracteres, pero exige de alguna manera una reducción en la expresión de las ideas, lo que lleva a un nivel pragmático muy restringido, casi meramente funcional y utilitario, donde se restringe la riqueza comunicativa, se obvian adjetivos, preposiciones y conjunciones, reduciendo o regresando más bien a la utilización de funciones básicas del lenguaje: Instrumentales, reguladoras o interactiva y perdiendo poco a poco la posibilidad de utilizar funciones más complejas como la ideacional, matética, heurística, etc.; las cuales quedarán muy posiblemente reservadas para otros niveles tal vez de carácter científico, académico o formal.

Cabe entonces otra pregunta ¿dónde quedan las normativas del lenguaje, o será tal vez que deberán coexistir sin interferencia el lenguaje normativo y el descriptivo como lo propone Martínez De Sousa, o serán las normas perversas las que regirán las expresiones comunicativas?

Parecería que definitivamente la Real Academia de la Lengua, deberá enfrentarse dentro de poco tiempo a una reestructuración y revisión profunda del uso del lenguaje escrito, pues si más allá de la normativa establecida nos veremos abocados a una comunicación tan simple y utilitaria por esta generación de escritores "on line", será urgente proponer nuevas medidas que sin matar la lengua, se adecúen a esta nueva realidad comunicativa producto de una nueva sociedad globalizada y sobrecomunicada.

\section{Conclusiones}

Se ha analizado la importancia y vigencia de las normas sociales como organizadoras, reguladoras y controladoras de la conducta de los individuos. Beramendi (2013) recapitula las posiciones de Hogg y Reid (2006), Bicchieri (2008), Cialdini y Trost (1998), Sherif (1936/1973) y Linares (2012) 
y afirma que las normas sociales son representaciones cognitivas de las conductas que se consideran apropiadas y generalmente valoradas por los sujetos, por tanto, son construcciones sociales que moldean y disponen el comportamiento, por lo que sirven como marco de referencia para las interacciones sociales y la emisión de juicios de valor (Beramendi, 2013, p. 7).

En tal sentido, las normas sociales no se establecen por imposición, pero son presentadas justamente a partir de la generalización de las mismas en el actuar cotidiano de la gente. Sin embargo, estas normas no siempre son cumplidas, lo que genera la desaprobación y en ocasiones el rechazo de la comunidad; al respecto, Fernández Dols (1992), plantea que las normas son incumplibles porque solo pueden cumplirse en términos ideales. En este sentido, las normas no son perversas porque en sí mismas sean imposibles de cumplir o sean intrínsecamente malas sino porque en el contexto en el que deberían actuar no puede ejercer una acción concreta (Beramendi, 2013, p. 21).

Como se ha podido observar a lo largo de este recorrido, el análisis de las normas sociales es complejo, tal como lo plantean Fent, Groeber y Schweitzer, que consideran:

La norma social, puede ser estudiada desde un nivel de análisis micro social hasta un nivel macrosocial. Sin embargo, a partir de varios estudios se esclareció que existe una relación entre dichos niveles de análisis, porque un individuo toma una decisión sobre la adhesión a una norma a partir de lo que rigen las normas sociales impuestas a nivel macrosocial. (...). Por lo tanto, el desarrollo a largo plazo de las normas sociales es el resultado de dinámicas individuales y colectivas dentro de un sistema social complejo (Fent, Groeber, y Schweitzer, 2007 (Beramendi, 2013, p. 37).

Las normas lingüísticas se enmarcarían justamente en este nivel microsocial, pues constituirían parte de una convención incluida en el sistema de reglas que hacen y mantienen la cohesión del grupo; y se enmarca en el nivel macrosocial, en la medida en que la función del hablante es acatar la norma (Martínez De Sousa, 2003).

El modelo TECNO sobre el incumplimiento normativo, aunque fue presentado para explicar el incumplimiento de las normas sociales, al ser entendido como un proceso individual de cada sujeto, permitiría explicar de alguna manera el porqué del presente estudio: el uso del lenguaje, y su fundamento podría ser aplicado a las normas lingüísticas, en el sentido que la dimensión de protección haría referencia a la protección del lenguaje frente a los procesos expresivos y la de formalidad como la RAE presenta estas para normar el uso de la lengua castellana.

Ahora bien como lo afirma (Martínez De Sousa, 2003), la academia no es la creadora del lenguaje, sino que es la testigo del uso de la lengua, el 
que está determinado por la herencia cultural y tiene un carácter social, y es en esta interacción donde se debe considerar los actos comunicativos de los sujetos, las funciones del lenguaje abarcan la totalidad de las opciones de actos comunicativos, y en cada una de ellas, a pesar de existir normas explícitas para su expresión o transmisión, las funciones pueden verse distorsionadas por la contravención de la misma. Así pues, la normativa lingüística está manifestada a través las diversas alternativas que rigen el correcto uso de la gramática española, pero las normas descriptivas han variado sustancial y considerablemente sobre todo en los últimos años.

De ahí la instancia, a entender a los actos comunicativos también como procesos sociales donde la psicología social y la psicolingüística podrían trabajar en conjunto para comprender las causas de este incumplimiento normativo y generar propuestas que permitan un mantenimiento de nuestra lengua, pero a la vez un avance sincrónico con los cambios idiomáticos cada vez con mayor envergadura.

\section{Bibliografía}

BARREIRO, Alicia; BERAMENDI, Maite; ZUBIETA, Elena

2011 ¿Normas perversas en el ámbito educativo? aportes de la Psicología Social. Ciencia, Docencia y tenconología, XXII(42), 137-154.

BERAMENDI, M. \& ZUBIETA, E.

2014 Construcción y validación de la escala de percepción del sistema normativo. Revista Mexicana de Psicología, 31(2), 124-137.

BERAMENDI, $M$.

2013 Percepción el sistema normativo, transgresión y sus correlatos psicosociales en Argentina. (Tesis Doctoral Universidad de Buenos Aires). Facultad de Psicología.

BICCHIERI, C.

2006 The grammar of Society. The nature of dynamics of social norms. Cambridge: Cambridge University Press.

BOSQUE, I. \& DEMONTE, V.

1999 Gramática descriptiva de la lengua española. Madrid: Espasa Calpe. BÜHLER, K.

1950 Teoría del Lenguaje. Madrid: Biblioteca Conocimiento del hombre. CHOMSKY, N.

1999 Estructuras sintácticas. Buenos Aires: Siglo XXI.

CIALDINI, R. \& KALLGREN, C.

1990 A focus theory of normative conduct: reclycing the concept of norms to reduce littering in public places. Journal of personality and social psychology,58(6),1015-1026.

CIALDINI, R.

2007 Descrptive Social norms as underappreciated sources of social control. Pshychometrica, 72(2), 263-268.

DEMONTE, $V$.

2003 La esquiva norma del español, sus funsiones y relaciones con la variación del estándar. Simposio Variación y Descripción. 
ELKARTEA, G.

2010 La estandarización de la lengua, la recuperación del euskara II. p. 11.

ELOSÚA, M. R.

2006 Procesos psicológicos básicos. Madrid: Mac Graw Hill.

ELSTER, J.

1997 El cemento de la sociedad: las paradojas del orden social. Barcelona: Gedisa.

ESPAÑOLA, R. A. d. 1. L.,

2010 Manual Nueva Gramática de la Lengua Española. Madrid: Espasa.

EYSENCK, $\mathrm{H}$.

2010 Psicología Cognitiva. s.l.:s.n.

FERNÁNDEZ DOLS, J.

1992 Procesos escabrosos en Psicología Social: El concepto de norma perversa. Aprendizaje Revista de Psicología Social, 7, 243-255.

1993 Norma Perversa: hipótesis teóricas. Psicothema, 5, suplemento, 91-101.

GÜELL, A. \& TENA, J.

2010 Hacia un concepto de norma social integrable en modelos de simulación social multi-agente. Seminario de Psicología Social y Analítica.

HERNÁNDEZ, F.

2006 Metodología de la Investigación Científica. México: Mac Graw Hill.

JAKOBSON, R.

1986 Ensayos de Lingüistica General. Buenos Aires: Planeta-Di Agostini.

MARTÍNEZ DE SOUSA, J.

2003 La contravención de la norma en el lenguaje. Disponible en: http://www.martinezdesousa.net/contravencion.pdf

MICOLICH, G.

2006 El uso social del lenguaje: Saussure y Wittgenstein. Encuentros y Divergencias, pp. 1-10.

MONTES, J.

1983 Habla, lengua e idioma. Centro Virtual Cervantes, TH. XXXVIII, 325-330.

OCEJA, L., ADARVES, I., FERNÁNDEZ, J.,

2001 Norma Perversa en Estudios de Ingeniería. Tarbiya Revista de investigación e Innovación Educativa, 27, 5-23.

OCEJA. L., VILLEGAS, M., \& BERAMENDI, M.

2013 Foco, Appraisal, Cálculo y Acción: Teoría Evaluativa de la Conducta Normativa. Manuscrito enviado para su publicación.

VAN DIJK, A.

1980 Texto y contexto: semántica y pragmática del discurso. Madrid: Ediciones Cátedra S. A..

Fecha de recepción del documento: 5 de marzo de 2016 Fecha de aprobación del documento: 5 de mayo de 2016 